\title{
Application of Liquid Chromatography Coupled with Electrospray Ionization Tandem Mass Spectrometry for Therapeutic Drug Monitoring of Sedative Medicine in Clinical Stage
}

\author{
Koichi INOUE ${ }^{1}$, Yuta OZAWA ${ }^{2}$, Toshimasa TOYO’OKA*2 \\ ${ }^{1}$ College of Pharmaceutical Sciences, Ritsumeikan University, 1-1-1 Nojihigashi, Kusatsu 525-8577, Japan \\ ${ }^{2}$ School of Pharmaceutical Sciences, University of Shizuoka, 52-1 Yada, Suruga-ku,
}

Shizuoka 422-8526, Japan

\begin{abstract}
Recent analytical advancements for sedative drug monitoring are a major topic in modern clinical stages. The liquid chromatography coupled with tandem mass spectrometry (LC-MS/MS) technique has been used for conventional therapeutic drug monitoring in the clinical stages. From the middle and late-2000s, LC-MS/MS with an electrospray ionization (ESI) interface has played an important role in pharmacokinetics, drug monitoring and metabolism studies since its introduction to the pharmaceutical industry and laboratory. Obviously, clinical researchers have needed highly sensitive, selective and accurate techniques for the sedative drug monitoring in various clinical stages. We review the current developments and reports regarding the application of LC-MS/MS with an ESI interface for sedative drug monitoring in the clinical stage.
\end{abstract}

Keywords: LC-MS/MS; ESI; TDM; Sedative drug

\section{Introduction}

Today, sedative drug monitoring is the most demanding work done by clinical researchers, governments, inspection agencies and international organizations. A drug's safety and useful events are a major concern not only for the proper utilization of medicines and related central nervous system agents, but also for the risk assessment derived from the excess administration, addictive substance, unfair use and unknown uses that might be triggered by anything detrimental to human health. Regarding sedative drug monitoring, the usual medicines, sedation involving benzodiazepine sedatives and propofol, are some of the trigger activities affecting an individual's and personal health. On the other hand, it is very important for the intensive care unit (ICU) to have excellent controlled pain and a sedating effect with fentanyl and/or dexmedetomidine for the serious patients. Thus, we can overcome this challenge facing personal negative effects that various administrations deigns can induce into the expanding cancer, chronic pain syndrome, surgery and ICU treatments, and should go directly into the secure studies to reduce any possible risk from sedative drugs. However, the big concern occurred when a sedative drug caused medical malpractice. In February 2014, the Japanese society conducted its survey after a 2-year-old boy on an artificial respirator died after receiving a propofol injection at Tokyo Women's Medical University Hospital. This propofol is the same one that killed well-known star Michael Jackson in an overdose case in 2009. We should need to dissipate the dissociation of clinical use and abuse liability based on the evidence from sedative drug monitoring.

The increased uses of sedative analgesics to treat chronic pain and the concomitant rise in excess administration are widely recognized trends. Moreover, sedative opioid analgesics are increasingly being used for the treatment of chronic noncancer pain [1]. In 2011, the US Food and Drug Administration (FDA) introduced mandatory safety measures for opioid prescribing, such as the Risk

Received: 1 June 2015

Accepted: 26 August 2015

J-STAGE Advance Published: 7 September 2015

DOI: $10.15583 /$ jpchrom.2015.020
*Corresponding author: Toshimasa TOYO'OKA

E-mail: toyooka@u-shizuoka-ken.ac.jp 
Evaluation and Mitigation Strategies [2]. Various organizations, including the American Pain Society, the American Academy of Pain Medicine, and the American Society of Interventional Pain Physicians, among others, have since developed clinical guidelines for responsible opioid prescribing [3-7]. The use of opioids, benzodiazepines, propofol, and/or other sedative drugs occurs at high rates among various patients with chronic pain despite the negative consequences of morbidity and mortality. There are increased rates of adverse events, overdose, and death when these drugs are used by not paying attention. On the other hand, partial physicians have realized how important the study of pharmacokinetics is when discussed and evaluated based on highly sensitive, selective, accurate and useful analytical techniques for the preventable risk of sedative drugs. The plasma concentrations of sedative drugs significantly differ and/or are at very trace levels, so the analytical method plays an important role in the study of pharmacokinetics. To the best of our knowledge, only one liquid chromatography coupled with tandem mass spectrometry (LC-MS/MS) technique for the determination of sedative drugs in human plasma has been recently published, but its application is relatively minor for clinical stages, and the specific reviews are not adequate for our clinical study. Drug monitoring assay has a long history of developing specific determinations and chromatographic techniques from the early 1980s to today. By the mid-1990s, the price and performance of an LC-single MS (LC-MS) instrument had been improved to the extent that clinical and biochemistry studies were able to take advantage of the new technology. There are a number of various clinical applications of LC-MS, and the technique is more generally applicable than gas chromatography coupled with mass spectrometry (GC-MS) due to the broader range of biological molecules and/or medicines that can be analyzed and the greater use of LC separations from biological matrices. The reasons for choosing LC-MS over LC with conventional detectors, such as other detections, are essentially the same as with GC-MS, namely a high specificity and the ability to handle complex mixtures. In the 2000s, LC-MS/MS has been generally purposed for the drug monitoring in basic and clinical studies. MS/MS detectors operate by converting the analyte molecules into an ionized state, with subsequent analysis of the ions and any fragment ions that are produced during the ionization process based on their mass to charge ratio $(\mathrm{m} / \mathrm{z})$. Moreover, the electrospray ionization (ESI) interface has been widely used for versatile, reasonable, selective, sensitive, efficient and stable ionization. Today, many clinical researchers are looking at ways related to LC-MS/MS with an ESI interface that could be used for treating many treatment and/or therapeutic strategies. Especially, analytical researchers working in the area of medicine and/or pharmaceuticals are pressing ahead with the structural reforms of LC-MS/MS that have only just started for sedative drug monitoring. Thus, we reviewed the current developments and reports regarding the application to the LC-MS/MS with an ESI interface for sedative drug monitoring in the clinical stage.

\section{Propofol}

Propofol (2,6-diisopropylphenol) is a short-acting intravenous anesthetic agent that is used for the induction and maintenance of anesthesia. Propofol has a high metabolic clearance rate and is rapidly eliminated from the body as its glucuronide metabolites or after hydroxylation of its phenyl ring [8]. The rapid clearance of propofol is due to its metabolism to glucuronide metabolites or hydroxylation of its phenyl ring followed by glucuronidation in the blood (Fig. 1-[A]) [9]. The quantification of propofol in human blood samples employed LC coupled with ultraviolet-visible spectroscopy (UV), fluorescence, electrochemical detections and GC-MS techniques [10-14]. On the other hand, for the LC-MS/MS techniques, a method was needed to avoid the difficulties for the ionization of propofol. Propofol had a much lower sensitively ionized in the positive ion mode than in the negative ion mode with either ESI or atmospheric pressure chemical ionization (APCI). Especially, the ESI efficiency of propofol is very low and leads to poorer detection limits than the APCI interface. This phenomenon is consistent with common practices for the ESI-positive ionization of phenols that occurred by proton addition which was inefficient due to the hydroxyl group as well as the slightly acid nature. In addition, based on the ionization and fragment pattern of propofol, APCI was selected over ESI as the best source for the LC-MS/MS technique for propofol [15]. Thus, in the APCI-negative ion mode, the product ion spectrum for propofol's $[\mathrm{M}-\mathrm{H}]^{-}$ion $(\mathrm{m} / \mathrm{z} 177)$ was used and revealed a fragmentation behavior (Fig. 1 -[B]) $[15,16]$. In the case of an alkyl substituted propofol, cleavage of the $\beta$ carbon bound to the substituent on the phenyl ring is well documented and always gives the major fragment ion $(m / z$ 161) [15]. Thus, the APCI was used for the ionization and multiple reaction monitoring (MRM) detection of propofol (deprotonation: $m / z \quad 177 \rightarrow 161$ ) in the negative mode [16]. Based on the LC-MS/MS with APCI interface detection of propofol in plasma, the limit of quantification (LOQ) value is $5 \mathrm{ng} / \mathrm{mL}$ [16]. On the other hand, the ESI interface detection would be needed with arranged ionization of propofol. Therefore, the LC-MS/MS quantification of propofol and its main metabolites in human blood was modified [9]. The mass spectra of propofol glucuronide and 1-quinol glucuronide showed deprotonated molecules $\left([\mathrm{M}-\mathrm{H}]^{-}\right)$and prominent ions were observed at $\mathrm{m} / \mathrm{z} 177.2$ and $\mathrm{m} / \mathrm{z} 193.2$ corresponding to the 
loss of the glucuronide moiety in the ESI-negative mode [9]. However, the transition of propofol was preferred to the single ion monitoring (SIM) mode because the response was enhanced in the MRM $(m / z \quad 177.2 \rightarrow 177.2)$ mode [9].

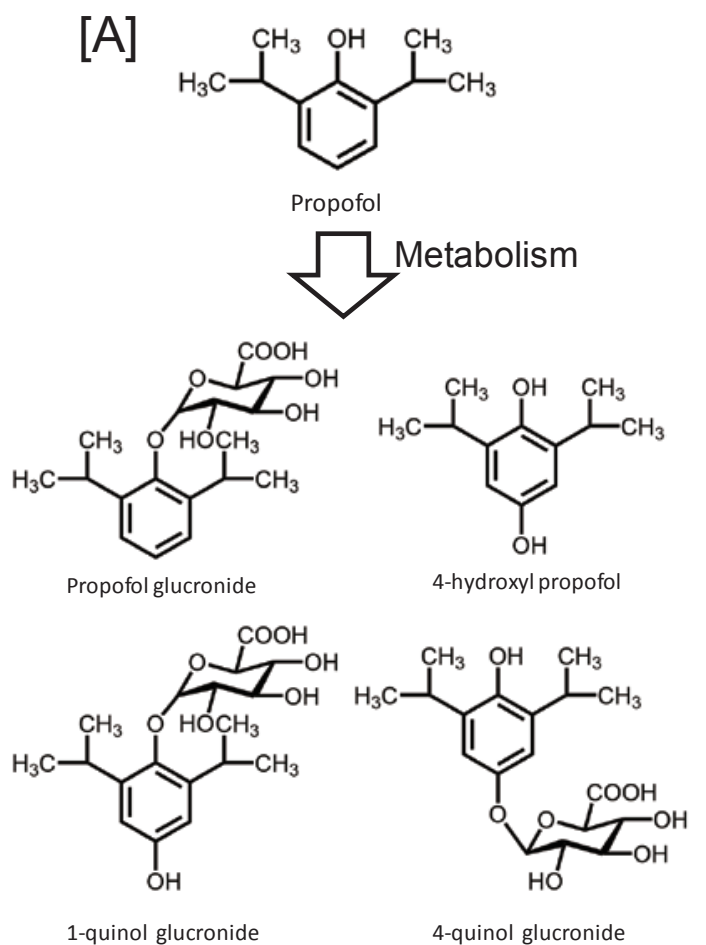

[B]<smiles>CC(C)c1cccc(C(C)C)c1O</smiles><smiles>C=Cc1cccc(C(C)C)c1[O-]</smiles>

4-quinol glucronide<smiles>CC(C)c1cccc(C(C)C)c1OS(=O)(=O)c1cccc2c(N(C)C)cccc12</smiles>

Dansyl chloride<smiles></smiles>

$N$-Methylpyridinium<smiles>CC(C)c1cc(/N=C/c2ccccc2)cc(C(C)C)c1O</smiles>

Azo-coupling reaction

Fig. 1. Metabolism, MS ionization fragmentation and derivatization of propofol for LC-MS/MS with an ESI interface. [A] Propofol indicates a high metabolic clearance rate and is rapidly eliminated from the body as its glucuronide metabolites or after hydroxylation of its phenyl ring [8]. [B] In the APCI-negative ion mode, the product ion spectrum for propofol's [M-H] $]^{-}$ion is used and revealed a fragmentation behavior [15,16]. [C] Various derivatization of propofol for LC-MS/MS in ESI-positive mode [18-20]. 
For this result, the LOQ of propofol is $10 \mathrm{ng} / \mathrm{mL}$ in plasma [9]. Recently, aggressive approaches were reported that the analysis of propofol in plasma using LC-MS/MS with an ESI interface in the negative MRM mode $(\mathrm{m} / \mathrm{z}$ $176.9 \rightarrow 160.9$ ) showed LOQ values of $270 \mathrm{ng} / \mathrm{mL}$ in rat plasma [17]. Thus, Beaudry et al. reported that propofol has a phenol group and can be chemically modified by a single step reaction with the common derivatization agent of dansyl chloride resulting in a product containing a tertiary amine (Fig. 1-[C]), which is easily protonated in the ESI-positive mode and can significantly improve the limit of detection of propofol [18]. The signal intensity of the propofol-dansyl chloride derivative was increased up to 50 -fold as compared to the underivatized propofol in the ESI-negative mode, and indicated LOQ values of $20 \mathrm{ng} / \mathrm{mL}$ in plasma [18]. For the LC-MS/MS analysis of propofol, the derivatization reaction by a one-step reaction under mild conditions is used. The approach based on the formation of $\mathrm{N}$-methylpyridinium derivatives of propofol (Fig. 1-[C]) showed a significant enhanced efficacy (approximately 300 -fold as compared to the underivatized propofol in the ESI-negative mode, $\mathrm{m} / \mathrm{z} 177 \rightarrow 177$ ) and an LOQ value of 13 $\mathrm{ng} / \mathrm{mL}$ in the ESI-positive mode [19]. Recently, Vaiano et al. reported an interesting derivatization of propofol in urine and blood samples using an azo-coupling reaction (Fig. $1-[\mathrm{C}]$ ) and indicated LOQ values of $0.003 \mathrm{ng} / \mathrm{mL}$ in the ESI-positive mode and $0.0004 \mathrm{ng} / \mathrm{mL}$ in the ESI-negative mode [20]. In an entirely different manner of propofol monitoring, the main metabolite glucuronide in biological samples is successfully used as a biomarker of propofol using LC-MS/MS with an ESI interface [21,22]. The therapeutic and detected levels of propofol in blood were about $1,000 \mathrm{ng} / \mathrm{mL}$ based on various cases [23]. During normal therapeutic drug monitoring (TDM), it is sufficient to use LC-MS with an ESI interface in the negative mode for the determination of propofol in biological samples. If the sensitivity and selectivity properties are needed, the derivatization of propofol in the positive mode is more intense than the direct analysis using LC-MS/MS with an ESI interface.

\section{Benzodiazepines}

Benzodiazepines have a broad range of medical effects such as sedative-hypnotics, anxiolytics, muscle-relaxants and anticonvulsants. The typical structures of the benzodiazepines are shown in Fig. 2. The sedative properties of various benzodiazepines are also considered useful for anesthesia control. In addition, the benzodiazepines have a rapid onset and a course of clearly-effective action combined with a low acute toxicity. On the other hand, benzodiazepines are also associated with abuse and some can be toxic at higher blood drug concentrations. Several metabolites of the benzodiazepines have pharmacological profiles similar to the original drugs. Their use might lead to the development of dependence, and the benzodiazepines are commonly used in combination with other substances of abuse [24]. Benzodiazepines are now among the most commonly prescribed drugs, which increases their potential for addiction and abuse in cases of crime, driving under the influence of drugs, suicide and drug-facilitated sexual assault [25,26]. Therefore, the analysis of benzodiazepines and their metabolites in human biological samples is of significant interest to clinicians and forensic toxicologists.

Benzodiazepines have been analyzed using LC-UV, GC and GC-MS. A significant number of benzodiazepines are polar and non-volatile compounds that have provision for GC and/or GC-MS techniques. In addition, some of the compounds cannot be derivatized for improved chromatographic behavior. Therefore, a significant breakthrough in the quantification of benzodiazepines and their metabolites was the application of LC-MS/MS techniques [27]. In a previous review, many LC-MS applications of benzodiazepines and their metabolites in various biological samples were introduced based on many references before 2011 [27]. Thus, recent topic reports from 2012 to 2014 were introduced in this review.

Recently, the "Z-drugs" (Fig. 2) has been the focus that is a group of non-benzodiazepines and has very effects similar is the benzodiazepines. Rust et al. reported that the quantification of 21 benzodiazepines and 3 "Z-drugs" in human hair was developed by two LC-MS/MS instruments (AB Sciex 3200 QTRAP and AB Sciex 5500 QTRAP with an ESI interface) [28]. Verplaetse et al. presented a highly sensitive LC-MS/MS method (AB Sciex 3200 QTRAP with an ESI interface) for the analysis of 27 analytes (benzodiazepines, benzodiazepine-like hypnotics and their metabolites) in urine and whole blood samples [29]. They indicated that ESI interface resulted in a higher ionization than APCI interface, as did a high $\mathrm{pH}$ mobile phase compared to a low pH mobile phase [29]. Montenarh et al. reported that a useful LC-MS/MS (AB Sciex 3200 QTRAP with an ESI interface) based on a simple liquid-liquid extraction was developed and validated for fast target screening and quantification of benzodiazepines and "Z-drugs" in the case of driving ability and crime responsibility in the three most important samples such as whole blood, plasma and serum [30]. These papers described the recent trend in the multi-analyte LC-MS/MS techniques for benzodiazepines, their metabolites and different drug classes in biological samples. Actually, a multi-analyte method for the quantification of 87 psychoactive drugs (antidepressants, antipsychotics, benzodiazepines, and "Z-drugs") in human hair has been developed and fully validated using LC-MS/MS (AB Sciex 4000 QTRAP with an ESI interface) [31]. 
Short-acting<smiles>CCc1cc2c(s1)N(C)C(=O)CN=C2c1ccccc1Cl</smiles>

Clotiazepam

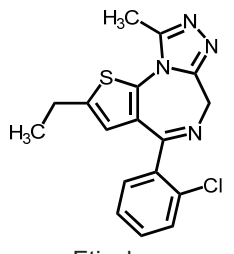

Etizolam

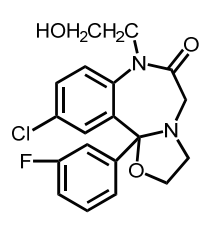

Flutazolam<smiles>O=C1CN=C(c2ccccc2)c2cc([N+](=O)[O-])ccc2N1</smiles><smiles>Cc1ncc2n1-c1ccc(Cl)cc1C(c1ccccc1F)=NC2</smiles><smiles>CN1C(=O)C(O)N=C(c2ccccc2)c2cc(Cl)ccc21</smiles>

Midazolam

Lormetazepam<smiles>CC[C@H]1C(C)=NN=C(c2ccc(OC)c(OC)c2)c2cc(OC)c(OC)cc21</smiles>

Tofizopam

Triazolam<smiles>Cc1nnc2n1-c1ccc(Cl)cc1C(c1ccccc1Cl)=NC2</smiles>

\section{Intermediate-acting}

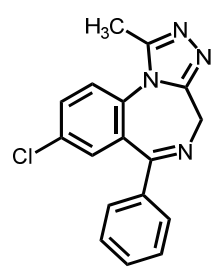

Alplazolam<smiles>CN1C(=O)CN=C(c2ccccc2F)c2cc([N+](=O)[O-])ccc21</smiles>

Flunitrazepam<smiles>CN1C(=O)C(O)N=C(c2ccccc2Cl)c2cc(Cl)ccc21</smiles><smiles>O=C1Nc2ccc(Cl)cc2C(c2ccccc2)=NC1O</smiles><smiles>O=C1Nc2ccc(Cl)cc2C(c2ccccc2Cl)NC1O</smiles>

Lolazepam<smiles>O=C1CN=C(c2ccccn2)c2cc(Br)ccc2N1</smiles>

Bromazepam

Long-acting<smiles>ONc1cc(O)c2cc(Cl)ccc2n1</smiles>

Chlordiazepoxide<smiles>O=C1CC2CCCCC2(c2ccccc2Cl)Nc2ccc(Cl)cc21</smiles>

Cloxazolam<smiles>C[C@@H]1C(c2ccccc2)N=C(c2ccccc2)CN1C</smiles>

Diazepam<smiles></smiles>

Ethyl loflazepate

Flurazepam

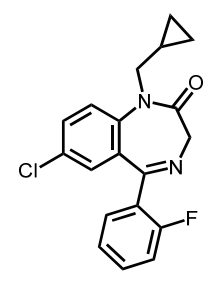

Flutoprazepam

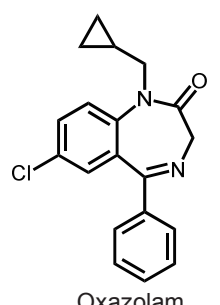

Oxazolam

Z-drugs
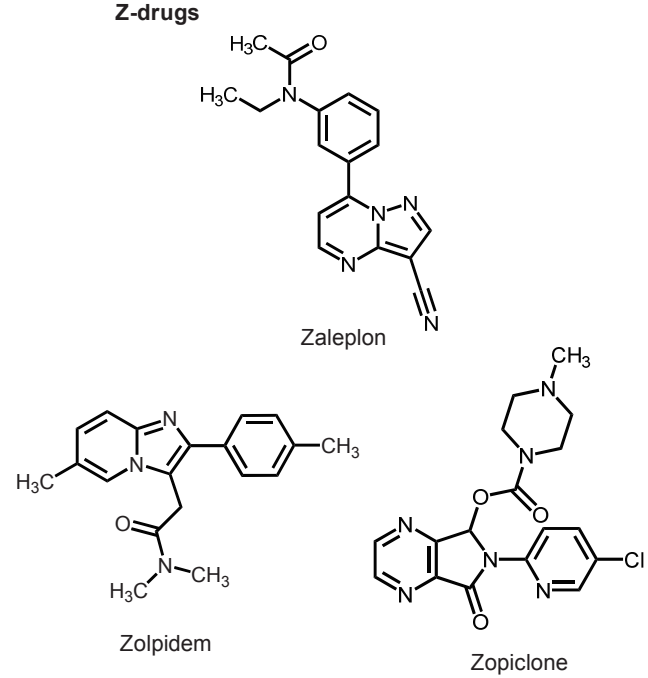

Zopiclone

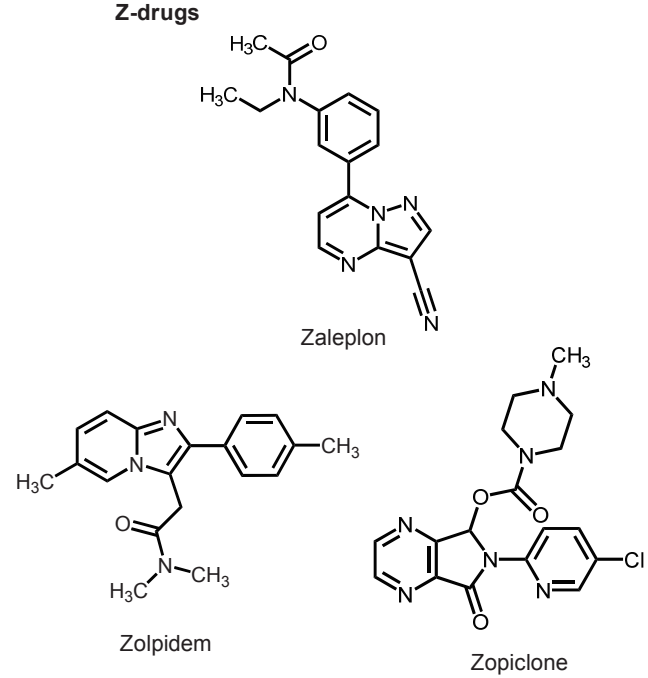<smiles>O=C1CN=C(c2ccccc2)c2cc(Cl)ccc2N1</smiles>

Prazepam<smiles>CC1CN2CC(=O)Nc3ccc(Cl)cc3C2(c2ccccc2)N1</smiles>

Nordazepam
Zolpidem

Fig. 2. Reported typical structures of benzodiazepines and Z-drugs. 
Montenarh et al. reported that a multi-analyte LC-MS/MS (AB Sciex 4000 QTRAP with an ESI interface) approach using one single work-up approach in whole blood, plasma, serum, post-mortem blood, liver tissue, gastric content, hair and urine was developed for the fast target screening and reliable identification of 130 analytes often requested in clinical and forensic toxicology [32]. This multi-analyte trend will be continued for the screening and high throughput detection of benzodiazepines in clinical and forensic toxicology.

We feature the highlights in analytical techniques to simultaneously measure benzodiazepines and their metabolite using hydrophilic interaction liquid chromatography (HILIC) separation. This method has been reported for the determination of alprazolam and their metabolite ( $\alpha$-hydroxy alprazolam) by HILIC with single ESI-MS [33]. HILIC in combination with ESI-MS and MS/MS detections has been steadily gaining acceptance for the analysis of polar compounds (such as metabolites) in complex biological matrices. The aim of the current HILIC study was to develop a sensitive, fast and convenient method for the simultaneous quantification of various drugs and metabolites from biological samples in the clinical stage.

\section{Opioids}

Opioids have a wide range of pharmacological effects such as analgesia, sedation, respiratory depression, decreased gut motility and cough depression in the clinical stage. Especially, opioids are clinically used in the relief of moderate and/or severe pain for palliative treatment, and sedative hypnotic for operative/ICU treatments. Morphine was an early potent narcotic analog with its main clinical use for the treatment of severe pain in cancer patients. Recently, various opioids, such as fentanyl, oxycodone, pethidine, buprenorphine, pentazocine, remifentanil, tramadol and naloxone, have been used for the treatment of sedative effects in various patients.

There is a requirement in the clinical stage to provide sensitive and selective methods for the identification and quantification of opioids and metabolites in biological samples. Thus, the analytical assays of opioids in biological samples have been developed for clinical, pharmaceutical and forensic purposes. Immunological methods for the qualitative and quantitative analysis of opioids are commercially available for the screening test of specific biological samples. When a positive result is detected by the immunological method, the confirmation is typically accomplished by the GC-MS technique. These immunological and GC-MS techniques provide useful, rapid and sensitive analytical evaluations of opioids, but it requires rechecking the cross reaction, hydrolysis of sample and derivatization. Thus, LC-MS techniques have been used for the qualitative and quantitative analyses of opioids in biological samples.

In 1995, LC-MS with an ESI interface was first applied for the pharmacokinetic studies of morphine metabolism in human and animal models [34]. In this study, the SIM mode was used and monitored: $\mathrm{m} / \mathrm{z} 286[\mathrm{M}+\mathrm{H}]^{+}$for morphine, $\mathrm{m} / \mathrm{z} 300$ for codeine (internal standard), $\mathrm{m} / \mathrm{z} 342$ for naltrexone (internal standard), and $m / z \quad 462[\mathrm{M}+\mathrm{H}]^{+}$for morphine 3- and 6-glucuronides [34]. Morphine is readily absorbed from the gastrointestinal tract, and metabolized by conjugation with glucuronic acid to the inactive morphine-3-glucuronide and morphine-6-glucuronide. In addition, the morphine-6-glucuronide is not present in animal models. Thus, for the human sample, the simultaneous determination of morphine, morphine-3-glucuronide, morphine-6-glucuronide and/or others was developed using LC-MS with an ESI interface [35-39]. First technique was reported for the simultaneous determination of morphine, morphine-3-glucuronide and morphine-6-glucuronide in human plasma [40]. In the MS/MS fragment, glucuronide metabolites both showed intense collision-induced dissociation (CID) product ions corresponding to the loss of glucuronic acid yielding the unconjugated morphine $(m / z 462 \rightarrow m / z$ 286) [40,41]. On the other hand, the transmission of morphine is the same ion $(m / z 286 \rightarrow m / z 286)$ through the CID, because the intensity of the fragment ions was very weak degree compared to the protonated ion $(m / z$ 286) [40,41]. The ESI-positive mode (Quattro Ultima: the source temperature was set to $130^{\circ} \mathrm{C}$, the desolvation temperature to $400^{\circ} \mathrm{C}$, gas $\left(\mathrm{N}_{2}\right)$ flow and desolvation gas $\left(\mathrm{N}_{2}\right)$ flow of 280 and 1180 $\mathrm{L} / \mathrm{min}$ ) showed the MS/MS transition of $\mathrm{m} / \mathrm{z} 286 \rightarrow \mathrm{m} / \mathrm{z}$ 152 for morphine [42]. In addition, the collision energy of 35 V (LCQ Deca XP Plus) in the ESI-positive mode showed the MS/MS transition of $m / z 286 \rightarrow m / z 201 / 229$ for morphine [43]. Liao et al. indicated another $\mathrm{MS} / \mathrm{MS}$ transition of $m / z 286 \rightarrow m / z 165$ [44]. Hybrid quadrupole linear ion-trap LC-MS technique (2000 QTRAP) showed that the transition of morphine is $\mathrm{m} / \mathrm{z} 286 / 286, \mathrm{~m} / \mathrm{z} 286 / 201$ and $m / z$ 286/165 [45]. Recently, the high resolution MS/MS

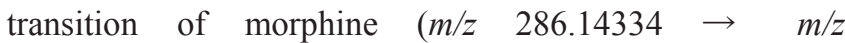
201.1/229.1) was reported using LTQ FT Orbitrap with an ESI interface [46]. Thus, if the morphine is analyzed using an ESI-MS/MS instrument, the MS parameters, such as the source temperature, desolvation temperature, gas flow, desolvation gas and collision energy, should be investigated for the optimal conditions of each instrument. Typical MS/MS spectra of morphine, oxycodone and fentanyl were determined by MS/MS (Micromass Quattro Premier) with an ESI interface and shown in Fig. 3. 


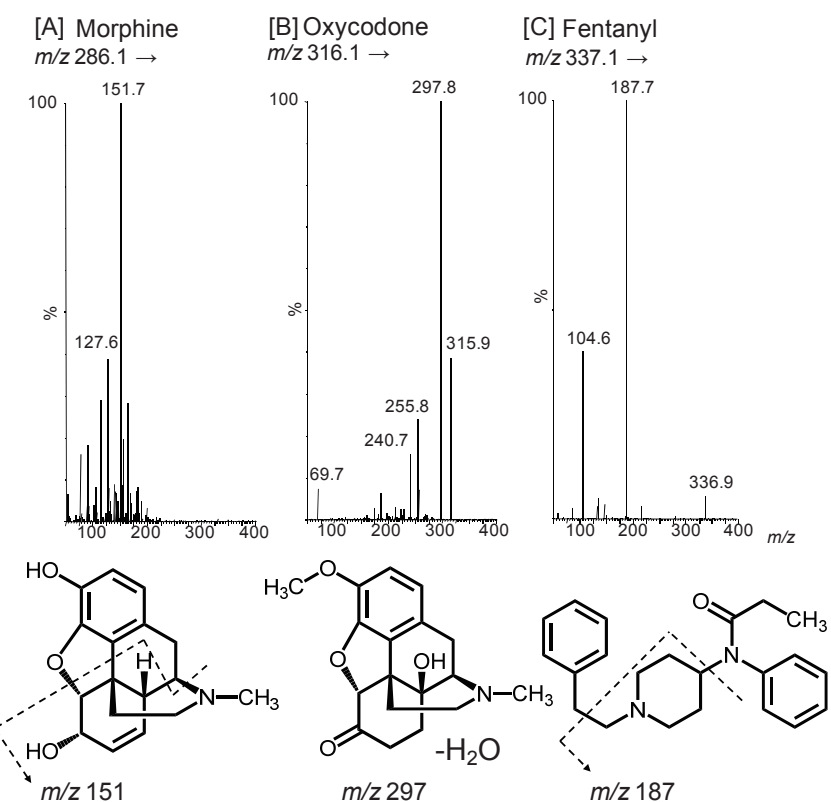

Fig. 3. MS/MS spectra of morphine, oxycodone and fentanyl using ESI-positive mode.

[A] MS/MS spectrum and fragment pattern of morphine.

[B] MS/MS spectrum and fragment pattern of oxycodone.

[C] MS/MS spectrum and fragment pattern of fentanyl.

Fentanyl (Fig. 4) is used very often in various clinical stages compared to the other opioids. In the 1980s, fentanyl was started to be introduced for widespread palliative use in the clinical and laboratory stages for patients and animal models. Thus, the development of early methods for the assay of fentanyl has been discussed. To measure fentanyl in the plasma of patients, it originally used GC with various detectors, but this technique has far exceeded by other methods. By the mid-1990s, there were a number of various clinical applications of LC-MS, and the technique is more generally applicable than GC-MS due to the broader range of biological molecules and/or medicines that can be analyzed and the greater use of LC separations from biological matrices. Thus, in the 2000s, LC-MS has been generally-purposed for the fentanyl monitoring in basic and clinical studies. For example, some configurations of fentanyl are far more versatile than others and the following descriptions focus on the major types of ion sources and mass analyzers likely to be used in LC-MS techniques within clinical laboratories. A high-throughput analysis of fentanyl in human plasma was developed by LC-MS/MS technique and a 96-well plate automated sample handling system [47]. Day et al. reported that LC-MS/MS with an ESI interface was developed for the simultaneous determination of fentanyl and norfentanyl in human plasma [48]. Fentanyl is cleared by hepatic biotransformation with minimal urinary excretion of the unchanged analog, and
$\mathrm{N}$-dealkylation to norfentanyl is the major metabolism route in humans [49]. Cytochrome P450 (CYP3A4) is the predominant enzyme responsible for human fentanyl metabolism by liver microsomes in vitro and in vivo. In addition, fentanyl is also metabolized by human intestinal microsomes, specifically by CYP3A4. Thus, the simultaneous detection of fentanyl and norfentanyl in biological samples is a useful and valuable TDM for the metabolic difference. Furthermore, Wang \& Bernert reported a sensitive, semiautomated and selective LC-MS/MS technique for the analysis of fentanyl and several of its metabolites (12 analytes) in human urine [50]. Obviously, the ionization pattern in the ESI-positive mode showed that fentanyl $\left(\mathrm{m} / \mathrm{z} 337,[\mathrm{M}+\mathrm{H}]^{+}\right)$was found in a single stage. The appearance of the MS/MS daughter ion scan (both an ion trap and a triple-quadrupole) indicated the fragmentation pathway of fentanyl $(m / z 337 \rightarrow m / z 188)$. This major product ion $(m / z 188)$ of fentanyl under MS/MS was accounted for by the neutral loss of $\mathrm{N}$-phenylpropanamide [51]. Thus, we have focused on the best way to indicate a drug's safety and useful events that are a major concern not only for the analytical utilization of medicines and related analogs, but also for the risk assessment derived from the excess administration, addictive substance, unfair use and unknown were in the clinical stages. It is natural that LC-MS/MS with an ESI interface is examined for the possibility of a clear vision and assay strategy of for fentanyl and other narcotic analgesic agents. Moreover, a simple, durable, economical and versatile screening assay of fentanyl has been needed and verified for the clinical fields. Thus, we restructured an accurate, useful and economical quantification of fentanyl in human serum that was performed using on-line solid phase extraction based on OASIS-HLB, reversed phase LC separation, and stable isotope dilution MS/MS with an ESI interface on the MRM mode [52]. This method has an advantage for fentanyl levels in serum from cancer patients in some therapeutic areas, such as neurology, psychiatry, and palliative treatment. Hisada et al. reported a simple LC-MS/MS technique for the screening assay of fentanyl in rats and patient plasma for the evaluation of cancer pain [53]. In the analysis of fentanyl by the MS/MS with an ESI interface, it is very easy to detect the selective, sensitive, useful and intense monitoring ion $(\mathrm{m} / \mathrm{z} 337 \rightarrow \mathrm{m} / \mathrm{z} 188)$ in the positive mode using reversed phase LC. Thus, it is not difficult to develop the simultaneous determination of fentanyl and its metabolites in biological samples using LC-MS/MS with an ESI interface. Actually, a recent paper showed that LC-MS/MS (API 4000) with an ESI interface was applied to quantify the distribution of fentanyl, norfentanyl, despropionylfentanyl and hydroxynorfentanyl in human plasma and urine samples [54]. Recently, to the best of our knowledge, a new chromatographic technique 
such as ultra-high-pressure LC (UHPLC) was developed and offered in speed, resolution and sensitivity compared to conventional LC techniques. For the selective assay of fentanyl and similar compounds, the UHPLC-MS/MS technique is performed to distinguish fentanyl and 16 other analogs in one chromatogram [55].
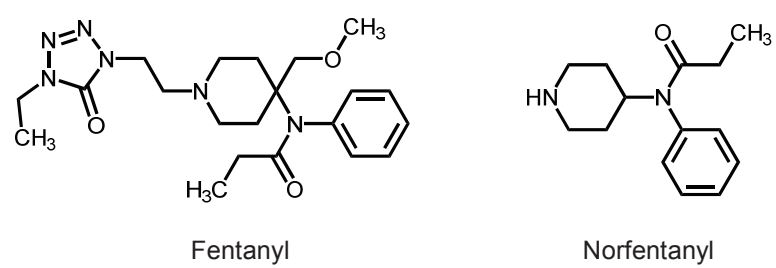

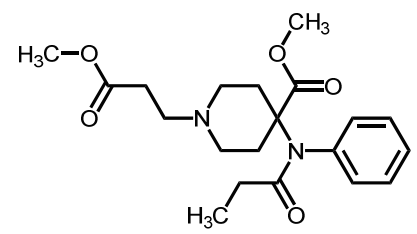

Remifentanyl

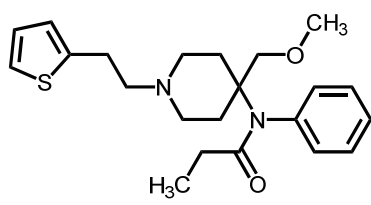

Sufentanil

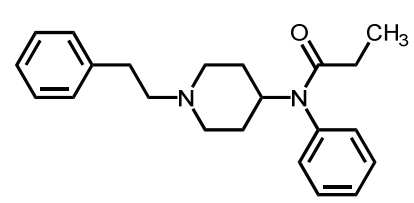

Alfentanil

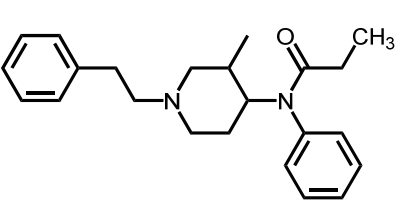

3-Methylfentanyl
Fig. 4. Reported typical structures of fentanyl analogs [64].

Remifentanil, a $\mu$-opioid agonist with a rapid onset and short sedative duration of action on the fentanyl class, has become a general anesthesia of infants, children, and adults in the ICU since it was approved by the FDA [56]. It has an in vivo elimination half-life of $9 \mathrm{~min}$ in patients, which is much shorter than other fentanyl analogs [57,58]. Several analytical methods have been developed to quantify remifentanil either alone or simultaneously with its major metabolite in whole blood using GC-MS and LC-MS techniques [59-61]. On the other hand, the quantification of remifentanil and/or its metabolites using LC-MS/MS with an ESI interface have been reported [17,62-65]. Using the LC-MS/MS with an ESI interface, the simultaneous quantification of fentanyl, norfentanyl, alfentanil, remifentanil, sufentanil and 3-methylfentanyl in plasma and urine occurred using fentanyl- $d_{5}$ and norfentanyl- $d_{5}$ as internal standards [64]. These structures of the fentanyl analogs are shown in Fig. 4. These LOQ values were ranged from 0.1 to $0.2 \mathrm{ng} / \mathrm{mL}$ in the positive mode [64]. However, there are a few reports regarding the monitoring of remifentanil in biological samples, because its metabolite and elimination are completed with an extremely short half-life.

These are by far the most analyzed biological samples for opioid administration in several fields, including clinical and forensic toxicology and workplace drug testing. This task is normally achieved using immunoassay procedures, and usually involves the application of each opioid's antibody for the specific interaction of each compound. However, this is low specificity that should be regarded as "within-group" specificity, meaning that a test cannot usually distinguish between two different opioids, such as morphine, from codeine, but can discriminate cocaine. However, single analyte tests are commercially available, and these are capable of such a differentiation. Thus, the recent trend has been indicated to those screening techniques that provide selective, sensitive, assured and simultaneous method capable of detecting the analytes at low concentrations using MS detectors [66-70]. We reviewed multi-analyte LC-MS/MS with an ESI interface procedures for screening, identification, and/or quantification of opioids, other drugs and/or their metabolites in biological samples in past two years (from 2012 to 2014) based on basic information such as analytes, LC column, mobile phase, and precursor/product ions of each procedure (Supporting information Table S1).

For future work to advance the development of potential field multi-analyte methods, a series of high priority matrices for under biological samples are reported on having been analyzed using high-performance ion mobility spectrometry (HPIMS) with an ESI interface to establish its detection capabilities [91]. Using a simplified sample preparation method, HPIMS with an ESI interface has successfully detected methamphetamine, MDMA, cocaine, morphine and other drugs in a urine sample [92]. Constructive analysis would proceed based on high performance LC methods using HPIMS with an ESI interface for the multi-analyte determination of opioids, their metabolites and/or other drugs in the clinical stages.

\section{Dexmedetomidine}

Dexmedetomidine is a selective central $\alpha_{2}$-agonist with anesthetics and analgesic properties. The elimination half-life of dexmedetomidine is $2 \mathrm{hr}$, and the $\alpha$-half-life is 6 min. The short half-life of dexmedetomidine makes it available as a preparation intended for intravenous administration. The FDA-approved indication for dexmedetomidine was the provision of short-term sedation $(24 \mathrm{hr}$ ) for adult patients in the ICU setting who were receiving mechanical ventilation with endotracheal intubation. On October 2008, dexmedetomidine received FDA approval for monitored anesthesia care in adults. Dexmedetomidine was then approved in Europe and Japan for the sedation of adults in the ICU. Notably, recent studies have reevaluated the efficacy and safety of 
dexmedetomidine as an anesthetic in infants and children $[93,94]$. Moreover, a sedative effect was investigated for pediatric nuclear medicine imaging [95]. Thus, there is a much-needed evaluation that the pharmacokinetics of dexmedetomidine in infants and/or children patients would be investigated using useful, sensitive and selective analytical techniques.

For the pharmacological study, first LC-MS/MS (API 4000) with an ESI interface was developed to simultaneously measure the concentrations of dexmedetomidine and its glucoronide metabolites in human plasma samples [96]. Subsequently, the maximum efficiency, confidence and sensitivity for very small amounts of blood from infant and/or children patients have been examined using LC-MS/MS with an ESI interface. In 2007, Lee et al. reported that the absolute recovery was $76.6-78.3 \%$ for dexmedetomidine in plasma using a small sample volume $(200 \mu \mathrm{L})$ with a lower LOQ of $5 \mathrm{pg} / \mathrm{mL}$ [97]. In 2009, Li et al. reported that LC-MS/MS with an ESI interface (TSQ Quantum) exhibited a linear range of 5 to $5000 \mathrm{pg} / \mathrm{mL}$ with a relative standard deviation of less than 15\% (absolute recovery: 87.2-89.5\%) based on an alkalinized plasma volume $(1000 \mu \mathrm{L})$ [97]. These internal standards used similar structures such as tolazoline and ondansetron [97,98]. Unfortunately, these clinical assays do not have realistic plans in the clinical field of pediatric trials. In 2013, we modified and rebuild the perfect and realistic LC-MS/MS (Xevo TQ-S) screening assay of dexmedetomidine in a small plasma sample for the clinical field of pediatric trials and ICU [99]. A highly accurate quantity was constructed using the original stable isotope dexmedetomidine- $d_{3}$ for the quantification of dexmedetomidine in very small plasma sample $(10 \mu \mathrm{L})$ from infant patients [99]. Currently, our LC-MS/MS screening assay was need for the clinical trials and specific TDM based on medical attendance in the ICU [100]. In 2014, LC-MS/MS (3200 QTRAP) with an ESI interface assay was developed and validated for the quantification of dexmedetomidine in pregnant ewes and fetuses [101].

\section{Future perspective}

As the LC-MS/MS with an ESI interface methodologies become more common place than distant stages, the cost and labor hour will be decreased in clinical laboratories. On the other hand, continual improvement of the immunological method means that the screening assay will be combined with the LC-MS/MS screening assay of various drugs in biological samples. By way of illustration, in 2013, the Rhode Island State Health Laboratories noticed an unusual pattern of toxicology results among 10 overdose deaths of suspected sedative drug users that had occurred during March to April, 2013 [102]. An enzyme-linked immunosorbent assay (ELISA) of fentanyl in the blood was used for the detection of fentanyl with positive detection in all cases. However, the GC-MS assay did not detect fentanyl in these blood samples. The mass spectrum was instead consistent with acetyl fentanyl, a fentanyl analog. Acetyl fentanyl, a synthetic opioid, has not been documented for illicit drug use or overdose deaths, and is not available as a prescription drug anywhere. Moreover, acetyl fentanyl is 15 times less potent than fentanyl, however, 40 and 80 times more potent than heroin and morphine, respectively. This drug has never been licensed for medical use and has only been sold illegally as a designer drug. On the other hand, a previous report showed that Canadian police discovered a group distributing over 3 kilograms and 12,400 pills of acetyl fentanyl equal to 117,400 doses. The Centers for Disease Control and Prevention (CDC) presented these data regarding acetyl fentanyl. Immediately behind the CDC report, they reported that the quantitative measurement of acetyl fentanyl and acetyl norfentanyl in human urine was developed using LC-MS/MS with an ESI interface [103]. This method showed that the sensitivity, accuracy and precision of assays of acetyl fentanyl and acetyl norfentanyl in human urine are adequate for clinical, public health and forensic applications [103]. For forensic and clinical purposes, the profiling of sedative drugs would be established for combined ELISA and LC-MS/MS methods in biological samples based on multi-analyte methods. Since its approval in various countries, the sedative drug has become increasingly popular for the medical management of pain and/or sedation and as a substance of abuse. Holistically, a review of the literature from the past decade has been published along with LC-MS/MS data for the determination and quantification of sedative drugs in biological samples. Future studies regarding the monitoring of sedative drugs would be indicated and discussed based on these reviewed papers for LC-MS/MS with an ESI interface.

\section{Supporting information}

Supporting information is available via the WEB at http://chromsoc.jp/Journal/SI.html.

\section{References}

[1] Quigley, C. Cochrane Database Syst. Rev. 2004, 3, CD004847.

[2] US Food and Drug Administration (FDA) FDA. http://www.fda.gov/ForConsumers/ConsumerUpdate s/ucm 251830.htm.

[3] Chou, R.; Fanciullo, G. J.; Fine, P. G.; Fine, P. G.; Adler, J. A.; Ballantyne, J. C.; Davies, P.; Donovan, M. I.; Fishbain, D. A.; Foley, K. M.; Fudin, J.; Gilson, A. M.; Kelter, A.; Mauskop, A.; O'Connor, P. G.; Passik, S. D.; Pasternak, G. W.; Portenoy, R. K.; Rich, B. A.; Roberts, R. G.; Todd, K. H.; Miaskowski, C. J. 
Pain 2009, 10, 113-130.

[4] The Management of Opioid Therapy for Chronic Pain Working Group. VA/DOD Clinical Practice Guideline for Management of Opioid Therapy for Chronic Pain. Washington, DC: Department of Veterans Affairs, Department of Defense. 2010.

[5] Manchikanti, L.; Abdi, S.; Atluri, S.; Balog, C. C.; Benyamin, R. M.; Boswell, M. V.; Brown, K. R.; Bruel, B. M.; Bryce, D. A.; Burks, P. A.; Burton, A. W.; Calodney, A. K.; Caraway, D. L.; Cash, K. A.; Christo, P. J.; Damron, K. S.; Datta, S.; Deer, T. R.; Diwan, S.; Eriator, I.; Falco, F. J.; Fellows, B.; Geffert, S.; Gharibo, C. G.; Glaser, S. E.; Grider, J. S.; Hameed, H.; Hameed, M.; Hansen, H.; Harned, M. E.; Hayek, S. M.; Helm, S. $2^{\text {nd }}$; Hirsch, J. A.; Janata, J. W.; Kaye, A. D.; Kaye, A. M.; Kloth, D. S.; Koyyalagunta, D.; Lee, M.; Malla, Y.; Manchikanti, K. N.; McManus, C. D.; Pampati, V.; Parr, A. T.; Pasupuleti, R.; Patel, V. B.; Sehgal, N.; Silverman, S. M.; Singh, V.; Smith, H. S.; Snook, L. T.; Solanki, D. R.; Tracy, D. H.; Vallejo, R.; Wargo, B. W. Pain Physician 2012, 15, S67-S116.

[6] Manchikanti, L.; Abdi, S.; Atluri, S.; Balog, C. C.; Benyamin, R. M.; Boswell, M. V.; Brown, K. R.; Bruel, B. M.; Bryce, D. A.; Burks, P. A.; Burton, A. W.; Calodney, A. K.; Caraway, D. L.; Cash, K. A.; Christo, P. J.; Damron, K. S.; Datta, S.; Deer, T. R.; Diwan, S.; Eriator, I.; Falco, F. J.; Fellows, B.; Geffert, S.; Gharibo, C. G.; Glaser, S. E.; Grider, J. S.; Hameed, H.; Hameed, M.; Hansen, H.; Harned, M. E.; Hayek, S. M.; Helm, S. $2^{\text {nd }}$; Hirsch, J. A.; Janata, J. W.; Kaye, A. D.; Kaye, A. M.; Kloth, D. S.; Koyyalagunta, D.; Lee, M.; Malla, Y.; Manchikanti, K. N.; McManus, C. D.; Pampati, V.; Parr, A. T.; Pasupuleti, R.; Patel, V. B.; Sehgal, N.; Silverman, S. M.; Singh, V.; Smith, H. S.; Snook, L. T.; Solanki, D. R.; Tracy, D. H.; Vallejo, R.; Wargo, B. W. Pain Physician 2012, 15, S1-S65.

[7] Utah Department of Health. Utah Clinical Guidelines on Prescribing Opioids for Treatment of Pain. Salt Lake City, UT: Utah Department of Health. 2009.

[8] Absalom, A. R.; Mani, V.; De Smet, T.; Struys, M. M. Br. J. Anaesth. 2009, 103, 26-37.

[9] Cohen, S.; Lhuillier, F.; Mouloua, Y.; Vignal, B.; Favetta, P.; Guitton, J. J. Chromatogr. B 2007, 854, 165-172.

[10] Dowrie, R. H.; Ebling, W. F.; Mandema, J. W.; Stanski, D. R. J. Chromatogr. B 1996, 678, 279-288.

[11] Knibbe, C. A.; Koster, V. S.; Deneer, V. H.; Stuurman, R. M.; Kuks, P. F.; Lange, R. J. Chromatogr. B 1998, 706, 305-310.

[12] Mazzi, G.; Schinella, M. J. Chromatogr. 1990, 528, 537-541.
[13] Dawidowicz, A. L.; Kalityński, R. Biomed. Chromatogr. 2003, 17, 447-452.

[14] Guitton, J.; Desage, M.; Lepape, A.; Degoute, C. S.; Manchon, M.; Brazier, J. L. J. Chromatogr. B 1995, 669, 358-365.

[15] Bajpai, L.; Varshney, M.; Seubert, C. N.; Stevens, S. M.; Johnson, J. V.; Yost, R. A.; Dennis, D. M. J. Am. Soc. Mass Spectrom. 2005, 16, 814-824.

[16] Bajpai, L.; Varshney, M.; Seubert, C. N.; Dennis, D. M. J. Chromatogr. B 2004, 810, 291-296.

[17] El Hamd, M. A.; Wada, M.; Ikeda, R.; Kawakami, S.; Kuroda, N.; Nakashima, K. Biomed. Chromatogr. 2015, 29, 325-327.

[18] Beaudry, F.; Guénette, S. A.; Winterborn, A.; Marier, J. F.; Vachon, P. J. Pharm. Biomed. Anal. 2005, 39, 411-417.

[19] Thieme, D.; Sachs, H.; Schelling, G.; Hornuss, C. J. Chromatogr. B 2009, 877, 4055-4058.

[20] Vaiano, F.; Mari, F.; Busardò, F. P.; Bertol, E. Anal. Bioanal. Chem. 2014, 406, 3579-3587.

[21] Kim, H. S.; Cheong, J. C.; Lee, J. I.; In, M. K. J. Pharm. Biomed. Anal. 2013, 85, 33-39.

[22] Kim, J.; In, S.; Park, Y.; Kim, E.; Lee, S. Anal. Bioanal. Chem. 2013, 405, 6807-6814.

[23] Han, E. Arch Pharm. Res. 2014, 37, 157-167.

[24] Fraser, A. D. Ther. Drug Monit. 1998, 20, 481-489.

[25] Drummer, O. H.; Gerostamoulos, J.; Batziris, H.; Chu, M.; Caplehorn, J.; Robertson, M. D.; Swann, P. Accid. Anal. Prev. 2004, 36, 239-248.

[26] Maurer, H. H. Anal. Bioanal. Chem. 2009, 393, 97-107.

[27] Nakamura, M. Biomed. Chromatogr. 2011, 25, 1283-1307.

[28] Rust, K. Y.; Baumgartner, M. R.; Meggiolaro, N.; Kraemer, T. Forensic. Sci. Int. 2012, 215, 64-72.

[29] Verplaetse, R.; Cuypers, E.; Tytgat, J. J. Chromatogr. A 2012, 1249, 147-154.

[30] Montenarh, D.; Hopf, M.; Maurer, H. H.; Schmidt, P.; Ewald, A. H. Anal. Bioanal. Chem. 2014, 406, 803-818.

[31] Fisichella, M.; Morini, L.; Sempio, C.; Groppi, A. Anal. Bioanal. Chem. 2014, 406, 3497-3506.

[32] Montenarh, D.; Hopf, M.; Warth, S.; Maurer, H. H.; Schmidt, P.; Ewald, A. H. Drug Test Anal. 2015, 7, 214-240.

[33] Kalogria, E.; Pistos, C.; Panderi, I. J. Chromatogr. B 2013, 942-943, 158-164.

[34] Pacifici, R.; Pichini, S.; Altieri, I.; Caronna, A.; Passa A. R.; Zuccaro, P. J. Chromatogr. B 1995, 664, 329-334.

[35] Tyrefors, N.; Hyllbrant, B.; Ekman, L.; Johansson, M.; Långström, B. J. Chromatogr. A 1996, 729, 279-285. 
[36] Schänzle, G.; Li, S.; Mikus, G.; Hofmann, U. J. Chromatogr. B 1999, 721, 55-65.

[37] Blanchet, M.; Bru, G.; Guerret, M.; Bromet-Petit, M.; Bromet, N. J. Chromatogr A 1999, 854, 93-108.

[38] Dienes-Nagy, A.; Rivier, L.; Giroud, C.; Augsburger, M.; Mangin, P. J. Chromatogr. A 1999, 854, 109-118.

[39] Toyo'oka, T.; Yano, M.; Kato, M.; Nakahara, Y. Analyst 2001, 126, 1339-1345.

[40] Slawson, M. H.; Crouch, D. J.; Andrenyak, D. M.; Rollins, D. E.; Lu, J. K.; Bailey, P. L. J. Anal. Toxicol. 1999, 23, 468-473.

[41] Mabuchi, M.; Takatsuka, S.; Matsuoka, M.; Tagawa, K. J. Pharm. Biomed. Anal. 2004, 35, 563-573.

[42] Bengtsson, J.; Jansson, B.; Hammarlund-Udenaes, M. Rapid Commun. Mass Spectrom. 2005, 19, 2116-2122.

[43] Murphy, C. M.; Huestis, M. A. J. Mass Spectrom. 2005, 40, 1412-1416.

[44] Liao, Q.; Deng, Y.; Xie, Z.; Pan, B.; Zhang, L. J. Sep. Sci. 2009, 32, 202-211.

[45] Taylor, K.; Elliott, S. Forensic. Sci. Int. 2009, 187, 34-41.

[46] Bijlsma, L.; Emke, E.; Hernández, F.; de Voogt, P. Anal. Chim. Acta 2013, 768, 102-110.

[47] Shou, W. Z.; Jiang, X.; Beato, B. D.; Naidong, W. Rapid Commun. Mass Spectrom. 2001, 15, 466-476.

[48] Day, J.; Slawson, M.; Lugo, R. A.; Wilkins, D. J. Anal. Toxicol. 2003, 27, 513-516.

[49] Tateishi, T.; Krivoruk, Y.; Ueng, Y. F.; Wood, A. J.; Guengerich, F. P.; Wood, M. Anesth. Analg. 1996, 82, 167-172.

[50] Wang, L.; Bernert, J. T. J. Anal. Toxicol. 2006, 30, 335-341.

[51] Peer, C. J.; Shakleya, D. M.; Younis, I. R.; Kraner, J. C.; Callery, P. S. J. Anal. Toxicol. 2007, 31, 515-521.

[52] Inoue, K.; Matsushita, S.; Nomura, M.; Tatemathu, M.; Mizuno, K.; Hino, T.; Oka, H. Jpn. J. Pharm. Palliat. Care Sci. 2011, 4, 111-116.

[53] Hisada, T.; Katoh, M.; Hitoshi, K.; Kondo, Y.; Fujioka, M.; Toyama, Y.; Ieda, H.; Gocho, S.; Nadai, M. Biol. Pharm. Bull. 2013, 36, 412-416.

[54] Mahlke, N. S.; Ziesenitz, V.; Mikus, G.; Skopp, G. Int. J. Legal. Med. 2014, 128, 771-778.

[55] Lurie, I. S.; Iio, R. J. Chromatogr. A 2009, 1216, 1515-1519.

[56] Welzing, L.; Roth, B. Drugs 2006, 66, 1339-1350.

[57] Egan, T. D.; Lemmens, H. J.; Fiset, P.; Hermann, D. J.; Muir, K. T.; Stanski, D. R.; Shafer, S. L. Anesthesiology 1993, 79, 881-892.

[58] Halliburton, J. R. AANA J. 1988, 56, 229-233.

[59] Grosse, C. M.; Davis, I. M.; Arrendale, R. F.; Jersey, J.; Amin, J. J. Pharm. Biomed. Anal. 1994, 12, 195-203.
[60] Bossù, E.; Montinaro, A.; Lecce, R.; Farina, A.; Suppa, E.; Draisci, G.; Gostoli, G. J. Pharm. Biomed. Anal. 2006, 42, 367-371.

[61] Kudo, T.; Kimura, F.; Kudo, T.; Kudo, M.; Hirota, K. J. Anesth. 2013, 27, 615-617.

[62] Zhang, C.; Zhang, L.; Zhang, X.; Yang, L.; Zhai, S.; Duan, L. Int. J. Clin. Pharmacol. Ther. 2008, 46, 477-488.

[63] Zhang, L. P.; Yang, L.; Bi, S. S.; Lu, W.; Zhang, X. H.; Zhai, S. D.; Duan, L. P. Chin. Med. J. 2009, 122, 1032-1038.

[64] Cooreman, S.; Deprez, C.; Martens, F.; Van Bocxlaer, J.; Croes, K. J. Sep. Sci. 2010, 33, 2654-2662.

[65] Said, R.; Pohanka, A.; Andersson, M.; Beck, O.; Abdel-Rehim, M. J. Chromatogr. B 2011, 879, 815-818.

[66] Maurer, H. H. Clin. Biochem. 2005, 38, 310-318.

[67] Maurer, H. H. Anal. Bioanal. Chem. 2007, 388, 1315-1325.

[68] Barroso, M.; Gallardo, E.; Vieira, D. N.; Queiroz, J. A.; López-Rivadulla, M. Anal. Bioanal. Chem. 2011, 400, 1665-1690.

[69] Moore, C.; Crouch, D. Bioanalysis 2013, 5, 1555-1569.

[70] French, D. Bioanalysis 2013, 5, 2803-2820.

[71] Hu, Z.; Zou, Q.; Tian, J.; Sun, L.; Zhang, Z. J. Chromatogr. B 2011, 879, 3937-3942.

[72] Gottas, A.; Oiestad, E. L.; Boix, F.; Ripel, A.; Thaulow, C. H.; Pettersen, B. S.; Vindenes, V.; Morland, J. J. Pharmacol. Toxicol. Methods 2012, 66, 14-21.

[73] Ruiz-Colón, K.; Martínez, M. A.; Silva-Torres, L. A.; Chavez-Arias, C.; Meléndez-Negrón, M.; Conte-Miller, M. S.; Bloom-Oquendo, J. J. Anal. Toxicol. 2012, 36, 319-326.

[74] Ghassabian, S.; Moosavi, S. M.; Valero, Y. G.; Shekar, K.; Fraser, J. F.; Smith, M. T. J.Chromatogr. B 2012, 903, 126-133.

[75] Kiss, B.; Bogdan, C.; Pop, A.; Loghin, F. Talanta 2012, 99, 649-659.

[76] Zancanaro, I.; Limberger, R. P.; Bohel, P. O.; dos Santos, M. K.; De Boni, R. B.; Pechansky, F.; Caldas, E. D. Forensic. Sci. Int. 2012, 223, 208-216.

[77] Schaefer, N.; Peters, B.; Schmidt, P.; Ewald, A. H. Anal. Bioanal. Chem. 2013, 405, 247-258.

[78] Bjørk, M. K.; Simonsen, K. W.; Andersen, D. W.; Dalsgaard, P. W.; Sigurðardóttir, S. R.; Linnet, K.; Rasmussen, B. S. Anal. Bioanal. Chem. 2013, 405, 2607-2617.

[79] De Castro, A.; Díaz, A.; Piñeiro, B.; Lendoiro, E.; Cruz, A.; López-Rivadulla, M.; Concheiro, M. Anal. Bioanal. Chem. 2013, 405, 4295-4305.

[80] Lin, H. R.; Chen, C. L.; Huang, C. L.; Chen, S. T.; 
Lua, A. C. J. Chromatogr. B 2013, 925, 10-15.

[81] Valtier, S.; Mueck, R. L.; Bebarta, V. S. J. Chromatogr. B 2013, 925, 40-45.

[82] Wu, X.; Zhang, W.; Bai, Y.; Guo, T.; Gu, J. J. Pharm. Biomed. Anal. 2013, 78-79, 261-268.

[83] Lin, H. R.; Choi, K. I.; Lin, T. C.; Hu, A. J. Chromatogr. B 2013, 929, 133-141.

[84] Wang, J.; Yang, Z.; Lechago, J. Biomed. Chromatogr. 2013, 27, 1463-1480.

[85] Regina, K. J.; Kharasch, E. D. J. Chromatogr. B 2013, 939, 23-31.

[86] Kim, J.; Ji, D.; Kang, S.; Park, M.; Yang, W.; Kim, E.; Choi, H.; Lee, S. J. Pharm. Biomed. Anal. 2014, 89, 99-105.

[87] Imbert, L.; Dulaurent, S.; Mercerolle, M.; Morichon, J.; Lachâtre, G.; Gaulier, J. M. Forensic. Sci. Int. 2014, 234, 132-138.

[88] Fernández Mdel, M.; Di Fazio, V.; Wille, S. M.; Kummer, N.; Samyn, N. J. Chromatogr. B 2014, 965 , 7-18.

[89] Fernández Mdel, M.; Wille, S. M.; Kummer, N.; Di Fazio, V.; Ruyssinckx, E.; Samyn, N. Ther. Drug Monit. 2013, 35, 510-521.

[90] Hegstad, S.; Hermansson, S.; Betnér, I.; Spigset, O.; Falch, B. M. J. Chromatogr. B 2014, 947-948, 83-95.

[91] Lapthorn, C.; Pullen, F.; Chowdhry, B. Z. Mass Spectrom. Rev. 2013, 32, 43-71.

[92] Midey, A. J.; Patel, A.; Moraff, C.; Krueger, C. A.; Wu, C. Talanta 2013, 116, 77-83.

[93] Yuen, V. M. Paediatr. Anaesth. 2010, 20, 256-264.

[94] Schnabel, A.; Reichl, S. U.; Poepping, D. M.; Kranke, P.; Pogatzki-Zahn, E. M.; Zahn, P. K. Paediatr. Anaesth. 2013, 23, 170-179.

[95] Mason, K. P.; Robinson, F.; Fontaine, P.; Prescilla, R. Radiology 2013, 267, 911-917.

[96] Ji, Q. C.; Zhou, J. Y.; Gonzales, R. J.; Gage, E. M.; El-Shourbagy, T. A. Rapid Commun. Mass Spectrom. 2004, 18, 1753-1760.

[97] Lee, J. I.; Su, F.; Shi, H.; Zuppa, A. F. J. Chromatogr. B 2007, 852, 195-201.

[98] Li, W.; Zhang, Z.; Wu, L.; Tian, Y.; Feng, S.; Chen, Y. J. Pharm. Biomed. Anal. 2009, 50, 897-904.

[99] Inoue, K.; Sakamoto, T.; Fujita, Y.; Yoshizawa, S.; Tomita, M.; Min, J. Z.; Todoroki, K.; Sobue, K.; Toyo'oka, T. Biomed. Chromatogr. 2013, 27, 853-858.

[100] Fujita, Y.; Inoue, K.; Sakamoto, T.; Yoshizawa, S.; Tomita, M.; Maeda, Y.; Taka, H.; Muramatsu, A.; Hattori, Y.; Hirate, H.; Toyo'oka, T.; Sobue K. J. Int. Care 2013, 1, 15.

[101] Cui, Z.; Chow, D. S.; Wu, L.; Lazar, D. A.; Rodrigo, R.; Olutoye, O. O.; Olutoye, O. A. J. Chromatogr. B 2014, 961, 13-19.
[102] Mercado-Crespo, M. C.; Sumner, S. A.; Spelke, M. B.; Sugerman, D. E.; Stanley, C. MMWR. Morb. Mortal. Wkly. Rep. 2014, 63, 531.

[103] Patton, A. L.; Seely, K. A.; Pulla, S.; Rusch, N. J.; Moran, C. L.; Fantegrossi, W. E.; Knight, L. D.; Marraffa, J. M.; Kennedy, P. D.; James, L. P.; Endres, G. W.; Moran, J. H. Anal. Chem. 2014, 86, 1760-1766. 